\title{
Advanced Dynamic Finite Element Analysis of a Skew Steel Railway Bridge
}

\author{
G. Kaliyaperumal ${ }^{*}$ B. Imam*, T. Righiniotis* \\ ${ }^{*}$ Faculty of Engineering and Physical Sciences, University of Surrey, Guildford, GU2 7XH, UK
}

Keywords: Steel railway bridge, dynamic analysis, field measurements, frequency, stresses

\begin{abstract}
The aim of this paper is to present advanced modelling techniques for dynamic analysis of steel railway bridges. Finite element analyses of a case study skew bridge are carried out and the results are compared with available field measurements. Initially, eigenvalue analyses of different models are carried out in order to obtain the fundamental mode shapes and bridge frequencies and to assess the capability of each model to capture the dynamic behaviour of the bridge. Single-span, three-span and full bridge models are investigated with different elements such as shell, beam and combination of these. Very good agreement between the fundamental dynamic properties of the bridge and empirical results is found. Following the eigenvalue analysis, time history dynamic analyses are carried out using the full bridge model. The analyses are carried out for different train speeds and the strain histories are compared with available field measurements. In terms of fatigue assessment, mean stress range values, obtained from the strain histories at selected locations on the bridge members are also compared to each other. The results show that a full bridge model using a combination of beam and shell elements is a reasonably accurate and computationally efficient way of capturing the dynamic behaviour of a bridge and estimating mean stress range for fatigue damage calculations.
\end{abstract}

\section{Introduction}

Dynamic analysis of railway bridges has received considerable attention during the last decades. This can be attributed to the considerable development the finite element (FE) method and the increase in the capabilities of computers. Static analyses of bridges can be easily carried out using the FE method. However, dynamic analyses are much more demanding and, therefore, optimum models which are capable of capturing dynamic behaviour reasonably well and with time efficiency need to be developed.

Dynamic effects on a bridge can have an effect on the ultimate limit state behaviour of the bridge by amplifying the maximum stresses experienced by different members. 
During design, dynamic amplification factors are usually employed in order to take into account dynamic effects and amplify the statically-calculated stresses. In many cases, these factors may be over-conservative. On the other hand, dynamic effects may also have an impact on the fatigue behaviour of a member or connection by increasing the stress ranges and number of stress cycles experienced by them. Since fatigue behaviour is very sensitive to applied stresses, an accurate estimation of the dynamic stresses in a bridge is fundamental towards its fatigue assessment.

A number of past studies have attempted to quantify the dynamic impact caused by trains on railway bridges [1-3]. In [2], the dynamic stresses were used to estimate the remaining fatigue life of different elements on a railway truss bridge. A number of other investigators have attempted to calibrate their finite element model of the bridge with field measurements [4-6]. In [4], eigenvalue analysis of a truss bridge was carried out to determine its fundamental mode shapes, and results obtained from dynamic analyses under the passage of a locomotive were compared with field measurements. The calibrated model was then used to assess the capacity of the bridge.

The majority of the dynamic studies on railway bridges have employed finite element models using beam/frame elements which may be sufficient for the prediction of the overall behaviour of bridges. However, beam/frame elements are not capable of capturing local connection behaviour and out-of-plane movements and distortions of girders which may be critical in the case of plate girder bridges. The out-of-plane distortions may induce secondary stresses in welded plate girder skew bridges, which may lead to fatigue damage [7-9]. 
The aim of this paper is investigate the effects of different modelling assumptions on the dynamic behaviour of steel bridges and to present guidelines on carrying out dynamic analyses on such bridges. As a case-study, a welded steel girder bridge, in which fatigue cracks have been detected on the connection between the stiffeners and main girders, is analysed. A number of finite element models of the bridge with different degrees of complexity, combining beam and shell elements, are developed. Initially, a number of eigenvalue analyses are performed in order to determine the dominant frequencies of the bridge. This is followed by linear, time-history analyses of the bridge under the passage of selected trains. The results are compared with analytical solutions as well as field measurements which were carried out under the passage of a test locomotive over the bridge [10]. It should be noted that recently, a fatigue evaluation of the case-study bridge considered in this paper was carried out elsewhere [10]. This paper, on the other hand, focuses on investigating the dynamic behaviour and dynamic characteristics of the bridge.

\section{Bridge Description and Finite Element Model}

The case-study bridge, which is shown in Fig. 1, is located in Stockholm, Sweden over the stream Söderström and was built in the mid-1950s. This is a railway bridge which connects northern and southern Sweden with two separate train tracks laid over wooden sleepers resting on the stringer beams. Almost 520 trains pass over this bridge every day, out of which commuter trains are the most frequent and freight trains are comparatively much less frequent.

The bridge is a welded, continuous steel girder skew bridge with six spans. Each span of the $190 \mathrm{~m}$, unballasted bridge varies in length between $26.9 \mathrm{~m}$ and $33.7 \mathrm{~m}$. The 
superstructure is composed of two main girders, $3000 \mathrm{~mm}$ deep and $600 \mathrm{~mm}$ wide and a floor-system of floorbeams $(1120 \mathrm{~mm}$ by $330 \mathrm{~mm})$ and stringers $(450 \mathrm{~mm}$ by $225 \mathrm{~mm})$. The cross beams have an orientation with the main girder at a skew angle of $80^{\circ}$. Inner and outer transverse web stiffeners are fillet-welded to main girders at equal spaces of $3370 \mathrm{~mm}$. Bracings are provided at two levels, one at the top to connect the rails and other at the bottom to connect the cross beams. Additional details regarding the bridge can be found in [10].

\subsection{Field Measurements}

After 50 years of its service, a number of cracks were observed in the bridge members and particularly at the connection between the stiffeners and the main girder web. Following the detection of cracks, the division of structural design and bridges at the Royal Institute of Technology (KTH) conducted field tests by passing a Rc6 locomotive over one track (west side track) of the bridge. The locomotive had a total weight of 78 tons and 4 axles with distance $2.7 \mathrm{~m}+5.0 \mathrm{~m}+2.7 \mathrm{~m}$ as shown in Fig. 2. Strains and accelerations were measured at different locations of span 7-8 (see Fig. 1), underneath the loaded track of the bridge, using 56 strain gauges and 5 accelerometers. Details of the strain gauge locations in span 7-8 are shown in Fig. 3a. Measurements were obtained at stringer and cross-girder mid-spans (points C, D, I), on the main girder (point A) and at the connection between the stringer and the cross-girder (point E). Fig. $3 \mathrm{~b}$ shows a typical cross section of a stringer at mid-span showing the points were measurements were carried out. As can be seen, measurements at four points (two on the top flange and two on the bottom flange) have been obtained. This was the case of all members i.e. stringers, cross-girders, main girders. 
The field measurements for the Rc6 locomotive were conducted at different speeds i.e. 1,10 and $52 \mathrm{~km} / \mathrm{h}$, the first speed $(1 \mathrm{~km} / \mathrm{h})$ representing effectively the case of static loading. The MGC plus system with amplifiers of the ML801 type produced by Hottinger Baldwin Messtechnik was used for the data acquisition. A typical measured strain history at point $\mathrm{S} 2$ of location $\mathrm{C}$ is shown in Fig. 4 for various locomotive speeds.

\subsection{Finite Element Model}

Finite element models of the bridge were developed using the commercial FE package ABAQUS [11]. Models with different degrees of complexity, using shell and/or beam elements were developed in order to investigate the effect of different modelling techniques and computational time on the dynamic behaviour of the bridge. Eightnoded, reduced integration shell elements (S8R) and three-noded, quadratic beam elements (B32) were used in the FE models. Single-span, three-span and six-span (full) bridge FE models were developed and analysed. Both simply supported (SS) and fixed support conditions were assumed in the single-span and three-span models at the two ends of the bridge in order to investigate the effect of boundary conditions. All members were tied to each other which is equivalent to assuming rigid connections between them.

One single-span bridge model using shell elements and one using beam elements was developed, representing span 7-8 of the bridge. The effect of bracings was also investigated via the single-span FE model by developing a shell model with and a model without bracings. Fig. 5 shows the shell-element model of the single span with the bracings included. In all the shell-element models, the stiffeners in the main girders were also modelled. In terms of the three-span bridge models, one model was developed 
using shell elements for all spans, as shown in Fig. 6 whereas the other model was developed by a combination of shell and beam elements. The latter model is shown in Fig. 7 where it can be seen that shell elements were employed for span 7-8 whereas beam elements were used to model the adjacent two spans. For the full bridge model, which is shown in Fig. 8, shell elements were used only for span 7-8, the remaining spans being modelled with beam elements. In both the three-span and six-span FE models, the intermediate supports were modelled as simply supported. In the latter two models, the shell elements of span 7-8 and the beam elements of the adjacent spans were connected through their centroids using multi-point constraints (MPCs) for all degrees of freedom and proper offsets. Due to the high computational effort required, a full-shell model of the entire bridge was not attempted.

\section{Eigenvalue analysis}

Eigenvalue analyses were carried out on all FE models of the bridge and the results, in the form of bridge periods (frequencies), were obtained and compared in order to assess the capability of different FE modelling detail levels on capturing fundamental dynamic properties of the bridge. Eigenvalues of an undamped mechanical system can be calculated based on the equation of motion which is given as

$$
[\mathrm{m}]\{\ddot{\mathrm{u}}\}+[\mathrm{k}]\{\mathrm{u}\}=\{0\}
$$

where $[\mathrm{m}]$ is the diagonal mass matrix, $[\mathrm{k}]$ is the square symmetrical stiffness matrix, $\{\mathrm{u}\}$ is the displacement vector, and $\{\ddot{\mathrm{u}}\}$ is the acceleration vector. After substituting $\{\mathrm{u}\}=\left\{\mathrm{u}_{j}\right\} \mathrm{e}^{i \omega_{j} \mathrm{t}}$ in Eq. (1), where $j$ is the $\mathrm{j}^{\text {th }}$ natural mode of harmonic vibrations with a circular frequency $\omega_{j}$, Eq. (1) becomes 


$$
\left([\mathrm{k}]-\omega_{j}^{2}[\mathrm{~m}]\right)\left\{\mathrm{u}_{j}\right\}=\{0\}
$$

From Eq. (2), the eigenvalues can be found by making the determinant equal to zero i.e. $[\mathrm{k}]-\omega_{j}^{2}[\mathrm{~m}] \mid=0$.

The bridge frequencies obtained from the FE analysis were compared with available empirical formulae suggested by Frỳba [12] and the International Union of Railways [13]. In [12], it is suggested that the first natural frequency $\left(f_{1}\right)$ for railway bridges of all types, materials and structural systems can be estimated by

$$
f_{1}=133 \times l^{-0.9}
$$

where $f_{1}$ is in Hertz, and $l$ is span of the bridge in meters. Specifically, for steel plate girder bridges without ballast, which is the type of bridge investigated in this paper, it has been suggested that [12]

$$
f_{1}=208 \times l^{-1}
$$

These empirical expressions were developed through statistical evaluation and regression analysis of a large number of field measurements of bridge frequencies carried out in the past on different type of ballasted and unballasted bridges such as steel truss, plate girder and concrete [12].

It has also been suggested that the first natural frequency of unloaded railway bridges of all types and materials should lie between the following limits [13,14]

i) lower limit (for $\operatorname{span} 20 \leq l \leq 100 \mathrm{~m}$ )

$$
f_{1}=23.58 \times l^{-0.592}
$$


ii) upper limit (for span $4 \leq l \leq 100 \mathrm{~m}$ )

$$
f_{1}=94.76 \times l^{-0.748}
$$

\section{Dynamic Analysis}

Following the eigenvalue analysis, which was employed to obtain the fundamental dynamic properties of the bridge, static and dynamic FE analyses under the passage of the Rc6 test locomotive (see Fig. 2) were carried out to investigate the overall dynamic behaviour of the bridge. Two different types of dynamic analyses i.e. modal dynamic and implicit dynamic were undertaken to investigate the suitability of each to capture the dynamic behaviour of the bridge. Explicit dynamic analysis is computationally much more demanding than implicit analyses and due to the large nature of the FE model, this type of analysis was excluded from this investigation. The difference between implicit and explicit dynamic analysis lies in the solution procedure of the dynamic equations of motion [11].

The fundamental equation of motion of the bridge system can be expressed in general form as

$$
[\mathrm{m}]\{\ddot{\mathrm{u}}\}+[\mathrm{c}]\} \dot{\mathrm{u}}\}+[\mathrm{k}]\{\mathrm{u}\}=\{\mathrm{F}\}
$$

where $[\mathrm{c}]$ is the damping matrix $=2 \zeta \omega_{j}[\mathrm{~m}],\{\mathrm{u}\}$ is the velocity vector, $\{\mathrm{F}\}$ is the force vector, $\zeta$ is the damping ratio $=v / 2 \pi$ and $v$ is the logarithmic decrement of damping. Field measurements of $v$ carried out on a large number of railway bridges have resulted in an empirical expression which relates the variable to the first natural frequency $f_{l}$ of the bridge as [12] 


$$
v=\frac{f_{1}}{10\left(1+\left(\frac{10}{f_{1}}\right)\right)}
$$

where $f_{l}$ is in Hertz.

The analyses were carried out on the full-span, beam-shell element FE model of the bridge (Fig. 8). A range of different train velocities were employed in the analyses and the results were compared with the available field measurements. The bridge was loaded with the test locomotive and the axle loads of the train $(195 \mathrm{kN})$ were applied directly to the top flange of the stringers ignoring any load distribution due to the effect of rails and sleepers. Loading was initiated from the start of span 5-6 since the field measurements showed that the investigated span 7-8 experienced the effect of the locomotive from that point onwards. It was then traversed in $1 \mathrm{~m}$ steps until the middle of span 6-7 from which point onwards a smaller step size of $0.5 \mathrm{~m}$ was used up to the middle of span 8-9 where the step was once again changed to $1 \mathrm{~m}$ until the locomotive exited the bridge. The loads were applied as triangular forces as shown in Fig. 9 which is suggested in [3] and [15]. Here the dynamic load factor is assumed equal to 1 [16]. It is here assumed that a node starts to feel the effect of a train axle of diameter $d_{\text {axle }}$ when the centreline of the axle is at a distance of $d_{\text {axle }} / 2$ before that node. An artificial damping of $5 \%$, a typical value for this type of bridges, was included by default in the implicit analysis. The modal dynamic analysis was carried out using 30 modes and a material damping ratio of $\zeta=2.6 \%$ which was obtained from Eq. (8) based on the first modal frequency of the full bridge. A static analysis of the bridge was also carried out to compare the results with the field measurements obtained under a train velocity of 1 $\mathrm{km} / \mathrm{h}$ which can effectively be considered as static loading. 


\section{Results and discussion}

\subsection{Eigenvalue analysis of bridge}

Single span bridge model

As a first step, only the span of the bridge where the field measurements were obtained (span 7-8, see Fig. 1) was modelled as a single span using shell elements. Fig. 10 shows the first mode shape behaviour of the bridge model without bracings, for two different boundary conditions i.e. simply supported (SS) and fixed, whereas Fig. 11 shows the first mode shape behaviour of the bridge with the bracings included in the model. It can be seen from Fig. 10 that the first mode shape obtained from the model without bracings is lateral bending with periods of 0.510 and 0.460 seconds for the SS and fixed boundary conditions, respectively. The addition of bracings in the model reduces the bridge period by $64 \%$ and $73 \%$ for the SS and fixed boundary conditions, respectively. This is an indication of the additional stiffness that is provided by the bracings and suggests that these should be modelled for the purposes of dynamic analyses. As a result, all subsequent analyses were carried out on models which included the bracing elements.

The inclusion of bracings in the bridge FE model with SS boundary conditions resulted in a vertical bending mode shape (see Fig. 11a). On the other hand, the mode shape in the fixed boundary condition model was found to be a combination of lateral bending and torsion (Fig. 11b). This shows that the fixed boundary condition model is able to capture the out-of-plane behaviour of the main members which was responsible for the observed fatigue cracking in the main girder web to stiffener connections. Comparing 
SS and fixed boundary conditions for the model with bracings, the latter results in a period which is $32 \%$ lower than the former.

For comparison purposes with the shell element model, a beam element model of the span under consideration was also developed and analysed. Fig. 12 shows the first mode shape obtained from the eigenvalue analysis which consists of vertical bending for both SS and fixed boundary conditions. The eigenvalue analysis for this model showed that, although they are computationally much cheaper, beam elements fail to capture the outof-plane and torsional deformations of the main bridge girders.

\section{Three-span bridge model}

The full-shell, three-span bridge model shown in Fig. 6 was developed as an attempt to increase the accuracy of obtained results. Fig. 13 depicts the first two modes shapes obtained from the eigenvalue analyses for two different boundary conditions at the two ends of the FE bridge model (SS and fixed). It can be seen that, irrespective of the boundary conditions, the first mode shape captures vertical bending of the bridge (Figures $13 \mathrm{a}$ and $13 \mathrm{~b}$ ). The fixed boundary condition results in a $20 \%$ reduction in the first period as compared to the SS case ( 0.181 vs. 0.151 seconds). The second mode obtained from the eigenvalue analysis captures the out-of-plane flexural and torsional behaviour of the main girders for both SS and fixed boundary condition assumptions.

In the case of SS boundary conditions, the first period of bridge was found to be very similar to the single-span model. On the other, in the case of fixed boundary conditions, modelling the bridge with three-spans resulted in an almost $20 \%$ increase in the bridge period as compared to the single-span model ( 0.123 vs. 0.151 seconds). 
As an attempt to reduce the time required for the analysis, the adjacent spans to the investigated span were modelled using beam elements, which are computationally cheaper than shell elements. Fig. 14 shows the first two modes shapes for the beam and shell element three-span bridge model for both boundary conditions. It can be seen that, similar to the full-shell element model described above, the first mode shape obtained for this model is vertical bending for both types of boundary conditions (see Fig. 14a and 14b). The second mode captures the torsional and out-of-plane deformation on the main girders which resulted in the observed fatigue problems on the bridge (see Fig. 14c and 14d). The effect of fixed boundary conditions is to reduce the first time period by 20\%. Comparing the beam-shell bridge FE model with the full-shell FE model in terms of the obtained periods, it was found that the former results in a slight decrease in the period by a maximum $7 \%$. This demonstrates the fact that, for time economy considerations, modelling the remaining spans of the bridge using beam elements does not decrease the accuracy of the results considerably.

\section{Full bridge model}

Fig. 15 shows the first four mode shapes obtained from the eigenvalue analysis for the full bridge FE model which was developed using shell elements for span 7-8 and beam elements for the remaining bridge. As it can be seen, the out-of-plane mode is captured here through mode 3 whereas the remaining modes all include vertical bending effects. This full-bridge model results in a fundamental period of 0.208 seconds which is considerably higher than the previous models. For the subsequent modes, small increases in the periods, as compared to the single- and three-span models, are also evident. This demonstrates the fact that for the purposes of dynamic analyses, modelling 
the entire bridge in the way shown in Fig. 8 can be expected to provide a good prediction of the dynamic behaviour of the bridge.

\section{Overall comparisons}

Table 1 presents an overview of the results obtained from the eigenvalue analysis using the different finite element models. The periods of the first three modes of each model as well as the time required for each analysis and the number of elements in each FE model are shown in the table. The table clearly shows the time saving achieved by using beam elements in the model. Comparing, for example, the analysis time for the threespan shell element model with its beam-shell counterpart, it can be seen that the analysis time required for the latter is almost one fifth of the time required for the former. In the case of the full bridge model, which is a combination of shell and beam elements, the time required for the analysis in almost half of that required for the three-span shell element model and is most probably significantly lower than the time that would be required for a full-shell entire bridge model considering the non-linear relationship between the size of the FE model (number of elements) and analysis time.

Table 2 shows the fundamental period obtained for the particular bridge being investigated through the available empirical formulae presented in section 3 . Comparison of the empirical values with the results obtained from the FE eigenvalue analyses presented in Table 1 reveals a good agreement between the two sets of results. The first natural frequency obtained from the full bridge model lies well within the upper and lower limits suggested by the UIC [13]. 


\subsection{Dynamic analysis of bridge}

The full-span bridge FE model was used to carry out a number of initial parametric dynamic analyses under the passage of the test locomotive and compare the results with the available field measurements in order to determine the type of dynamic analyses most appropriate. Both implicit and modal dynamic analyses using 30 modes were carried out using ABAQUS. The results obtained from the modal analysis did not show good agreement with the field measurements, therefore they are excluded from further discussion. Since the available field measurements included the case of a "static" passage of the test locomotive over the bridge by a velocity of $1 \mathrm{~km} / \mathrm{h}$, a static $\mathrm{FE}$ analysis of the bridge was also carried out.

Fig. 16 shows the comparison of the strain histories obtained from the static analysis with the field measurements at points $\mathrm{S} 1$ and $\mathrm{S} 2$ of location $\mathrm{C}$ (see Fig. 3), which is located at the mid-length of the stringer, under a velocity of $1 \mathrm{~km} / \mathrm{h}$. It can be seen that good overall agreement between the results is obtained with the static FE analysis predicting slightly higher maximum strains at the peak points.

Fig. 17 and 18 show comparison of the strain histories obtained from the implicit dynamic analysis under velocities of 10 and $52 \mathrm{~km} / \mathrm{h}$, respectively, with the field measurements under the same speeds. Good agreement can be seen between the results in the case of the dynamic analyses with very good prediction of the maximum strains. Although the implicit dynamic analysis captures the overall trend of the strain history well, it produces some additional smaller strain cycles which is, however, expected to be insignificant in terms of fatigue assessment and fatigue damage calculations. 


\section{Mean stress ranges}

The mean stress range at a detail can be viewed as an important parameter in terms of fatigue assessment. The strain histories obtained from the passage of the test locomotive over the bridge were converted in stress histories and these were then analysed using the rainflow counting procedure to obtain the stress range histogram and, therefore, $E\left[S_{r}\right]$ in $\mathrm{N} / \mathrm{mm}^{2}$. Mean stress ranges obtained at the mid-span and supports of the stringer and the main girder near to the loaded track of the bridge were compared. Fig. 19 shows these comparisons for three different train velocities, i.e. 1,10 and $52 \mathrm{~km} / \mathrm{h}$.

Fig. 19a with reference to locomotive speed of $1 \mathrm{~km} / \mathrm{h}$ (static case) shows that the stress ranges obtained from the $\mathrm{FE}$ static analysis are generally more conservative. The highest deviations were observed at the location of stringer midspans. From Fig. 19b and $19 \mathrm{c}$ it can be seen that there is a better agreement between the results obtained from the dynamic FE analysis and the field measurements for velocities of 10 and $52 \mathrm{~km} / \mathrm{h}$. The only exception is seen in Fig. 19b in the case of stringer supports where the highest deviations between the results are observed. Fig. 19c demonstrates that the dynamic implicit analysis is capable of capturing the mean stress range observed at various locations of the bridge with reasonable accuracy. Overall, the mean stress ranges obtained from the stringers of the bridge were higher than their main-girder counterparts.

The results presented in Fig. 19 and the good agreement of the mean stress range between field measurements and dynamic FE analysis under higher velocities is an indication that the fatigue life may be estimated with reasonable accuracy through results obtained from an FE model of a bridge in the form of Fig. 8 . 


\section{Conclusions}

Dynamic analyses of a case-study bridge in Sweden and comparison with available field measurements as well as eigenvalue analyses were presented in this paper. The eigenvalue analyses were carried out on a number of different FE models to investigate the effect of modelling assumptions on dynamic behaviour. It was found that secondary elements such as bracings may have a significant effect on the frequency of the bridge and it is suggested that they are modelled during an FE analysis. It was also found that in order to capture the out-of-plane and torsional behaviour of the main girders, which led to the development of fatigue cracks on the case-study bridge, shell elements should be used in the FE models, as beams are unable to capture such type of behaviour. Modelling the investigated span of a bridge using shell elements and the remaining spans using beam elements is suggested as a cheap and practical way of obtaining reasonably accurate results. Overall, good agreement between the dominant bridge frequencies obtained from the eigenvalue analysis and empirical results was observed.

Following the eigenvalue analyses, the full bridge FE model was analysed dynamically under the passage of the test locomotive with different velocities. The comparison of the results obtained from dynamic FE analyses with available field measurements showed that implicit dynamic analysis is a reasonable and computationally efficient method of capturing the dynamic behaviour of a bridge and obtaining dynamic stress histories. The results were found to be in good agreement in terms of strain histories, maximum strains/stresses as well in terms of mean stress ranges, the latter for the purposes of fatigue assessment. 


\section{Acknowledgements}

The work within the frame of the project described in this paper is carried out with a financial grant from the Research Fund for Coal and Steel (RFCS) of the European Community, granted under the contract Nr. RFSR-CT-2008-00033. The authors of this paper would like to sincerely acknowledge the division of structural design and bridges at the Royal Institute of Technology (KTH) Sweden and the Swedish Rail administration for providing the field measurements.

\section{References}

[1] Wiriyachai A, Chu K H, Garg V K. Impact study by various bridge models. Earthquake Eng and Str Dynamics 1982; 10: 31-45.

[2] Garg V K, Chu K H, Wiriyachai A. Fatigue life of critical members in a railway truss bridge. Earthquake Eng and Str Dynamics 1982; 10: 779-795.

[3] Gu G, Kapoor A, Lilley D M. Calculation of dynamic impact loads for railway bridges using a direct integration method. Proc. Inst Mech Eng Part F: J Rail and Rapid Transit 2008; 222: 385-398.

[4] Ermopoulos J, Spyrakos C C. Validated analysis and strengthening of a 19th century railway bridge. Eng Struct 2006; 28(5): 783-792.

[5] Spyrakos C C, Raftoyiannis I G, Ermopoulos J C. Condition assessment and retrofit of a historic steel-truss railway bridge. J Const Steel Research 2004; 60(8): 1213-1225.

[6] Caglayan B O, Ozakgul K, Tezer O. Fatigue life evaluation of a through-girder steel railway bridge. Eng Fail Analysis 2009;16(3): 765-774.

[7] Roddis W M K, Yuan Z. Finite-element Analysis of Steel Bridge DistortionInduced Fatigue. J Bridge Eng 2003; 8 (5): 259-266.

[8] Fisher J W, Keating P B. Distortion-induced fatigue cracking of bridge detail with web gaps. J Constr Steel Research 1989; 12(3-4): 215-228.

[9] Jajich D, Schultz. Measurement and analysis of distortion-induced fatigue in multigirder steel bridges. J Bridge Eng 2003; 8(2): 84-91.

[10] Leander J, Andersson A, Karoumi R. Monitoring and enhanced fatigue evaluation of a steel railway bridge. Eng Struct 2010; 32(3): 854-863.

[11] ABAQUS. Standard User's Manual Version 6.8. Hibbitt Karlsson \& Sorensen, Inc; 2009.

[12] Frỳba L. Dynamics of Railway Bridges. London : Thomas Telford, 1996.

[13] UIC 776-1 R. Loads to be considered in the design of railway bridges. International Union of Railways, 1979.

[14] BS EN 1991-2. Eurocode 1: Actions on Structures - Part 2: Traffic loads on bridges. British Standard Institution, UK: London, 2003.

[15] Goicolea J M, Dominguez J, Navarro J A, Gabaldon F. New dynamic analysis methods for railway bridges in codes IAPF and Eurocode 1. Proceedings of IABSE: Railway Bridges: Design, Construction and Maintenance, Madrid, 2002.

[16] Bakht B, Pinjarkar S G. Dynamic testing of highway bridges - a review, Transportation Research Record 1989; 1223: 93-100. 


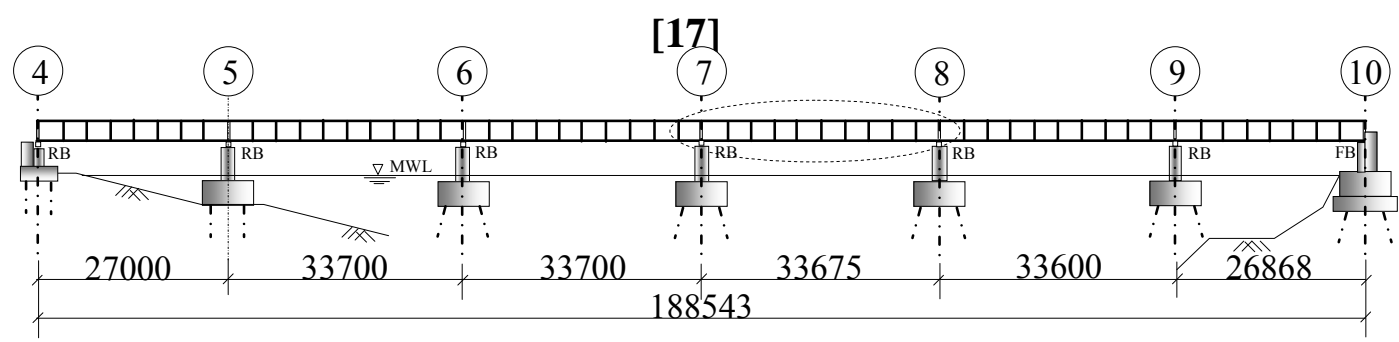

(a) Elevation view (RB - Roller Bearing and FB - Fixed Bearing)

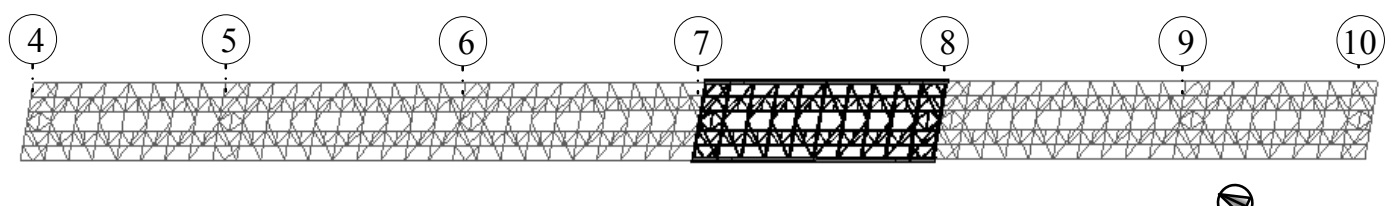

(b) Plan view (FE Model)

Fig. 1. Bridge over Söderström in Sweden (all dimensions are in $\mathrm{mm}$ ) 


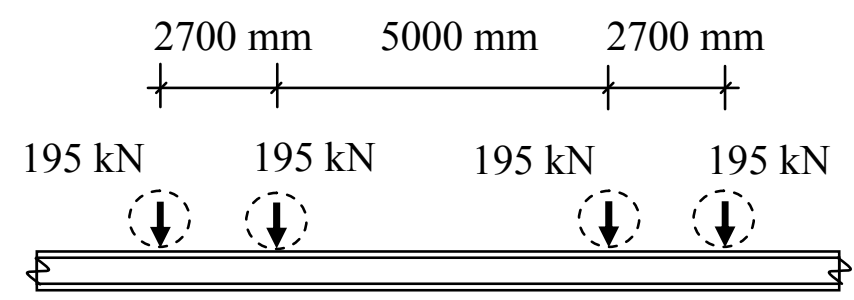

Fig. 2. Rc6 Locomotive load distribution on track 


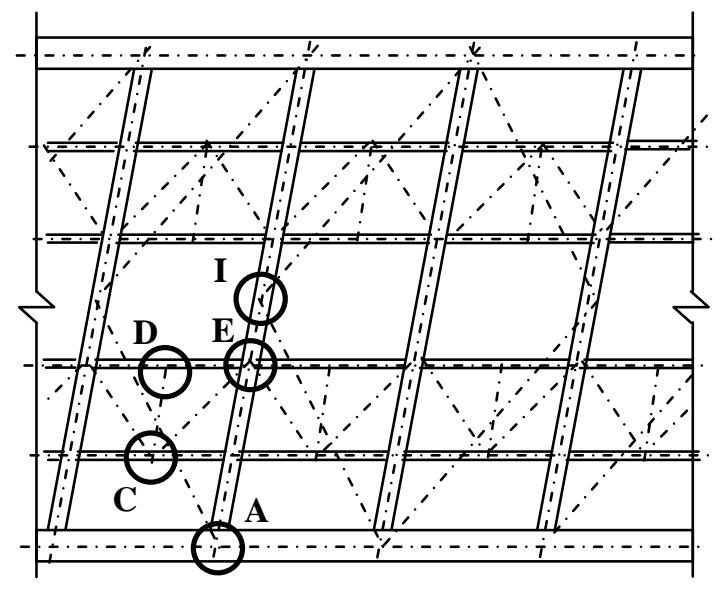

(a) Plan at mid-span

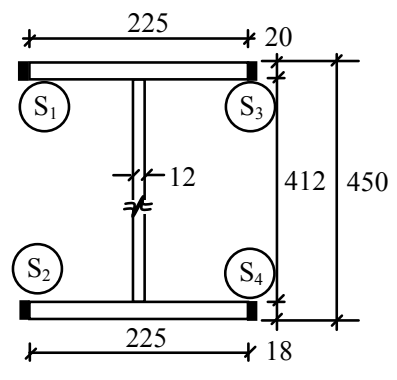

$\mathrm{S}_{1}, \mathrm{~S}_{2}, \mathrm{~S}_{3}$ and $\mathrm{S}_{4}$ are strain gauges (All dimensions are in $\mathrm{mm}$ )

(b) Cross-section at location $\mathrm{C}$

Fig. 3. Details of strain gauge locations at bridge span 7-8 


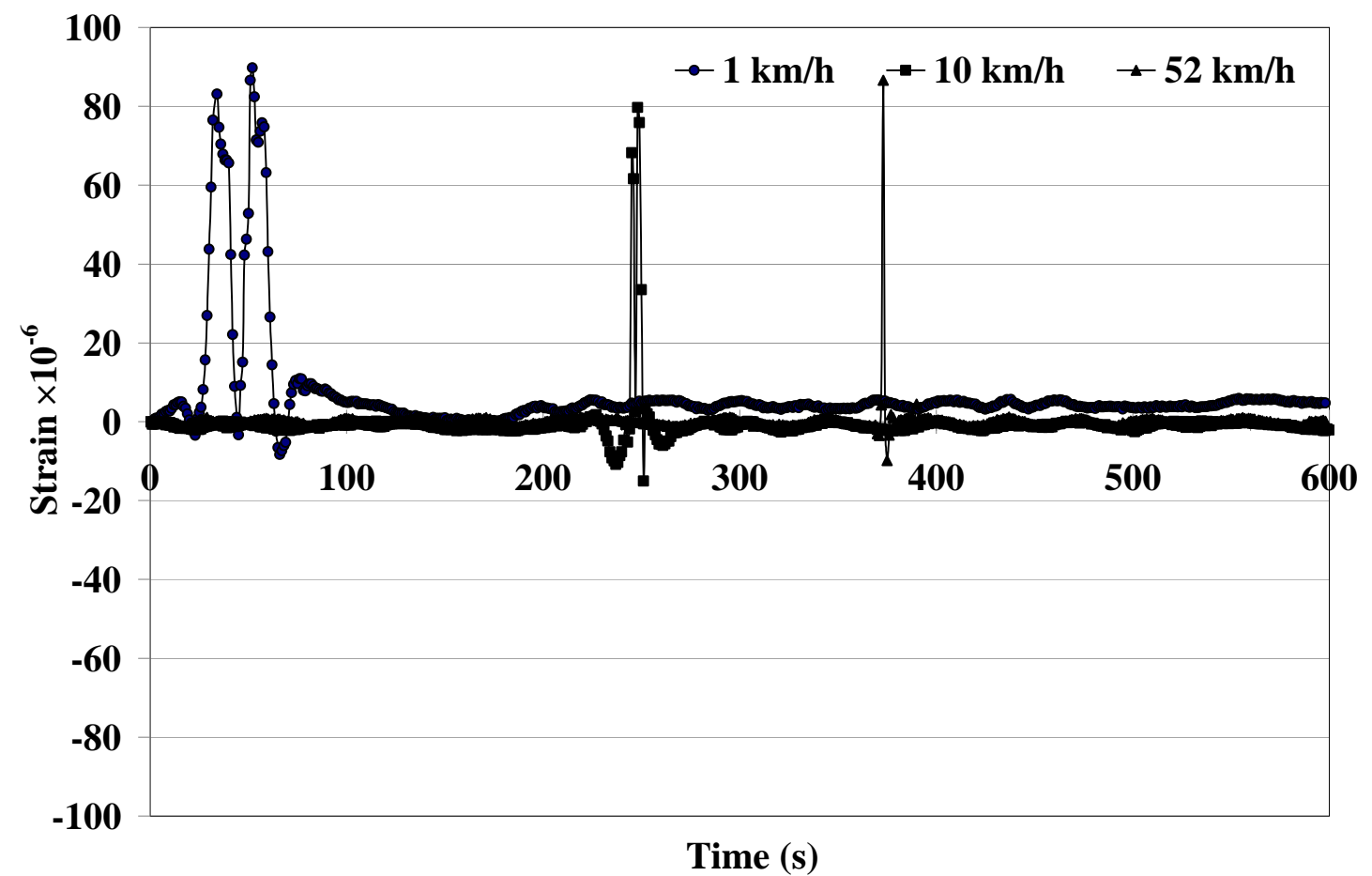

Fig. 4. Typical measured strain (at point $S_{2}$ ) for different locomotive speeds 


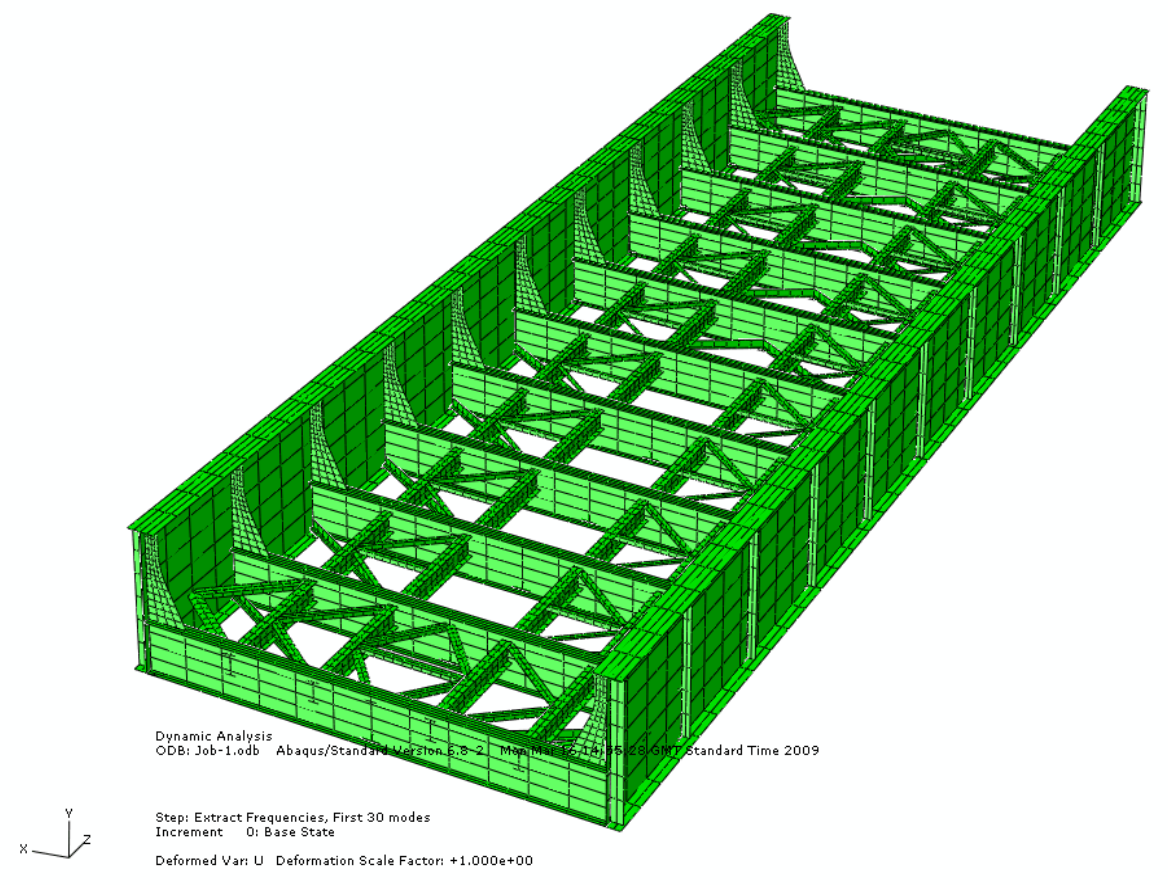

Fig. 5. Single-span shell element FE model of the bridge with bracings 


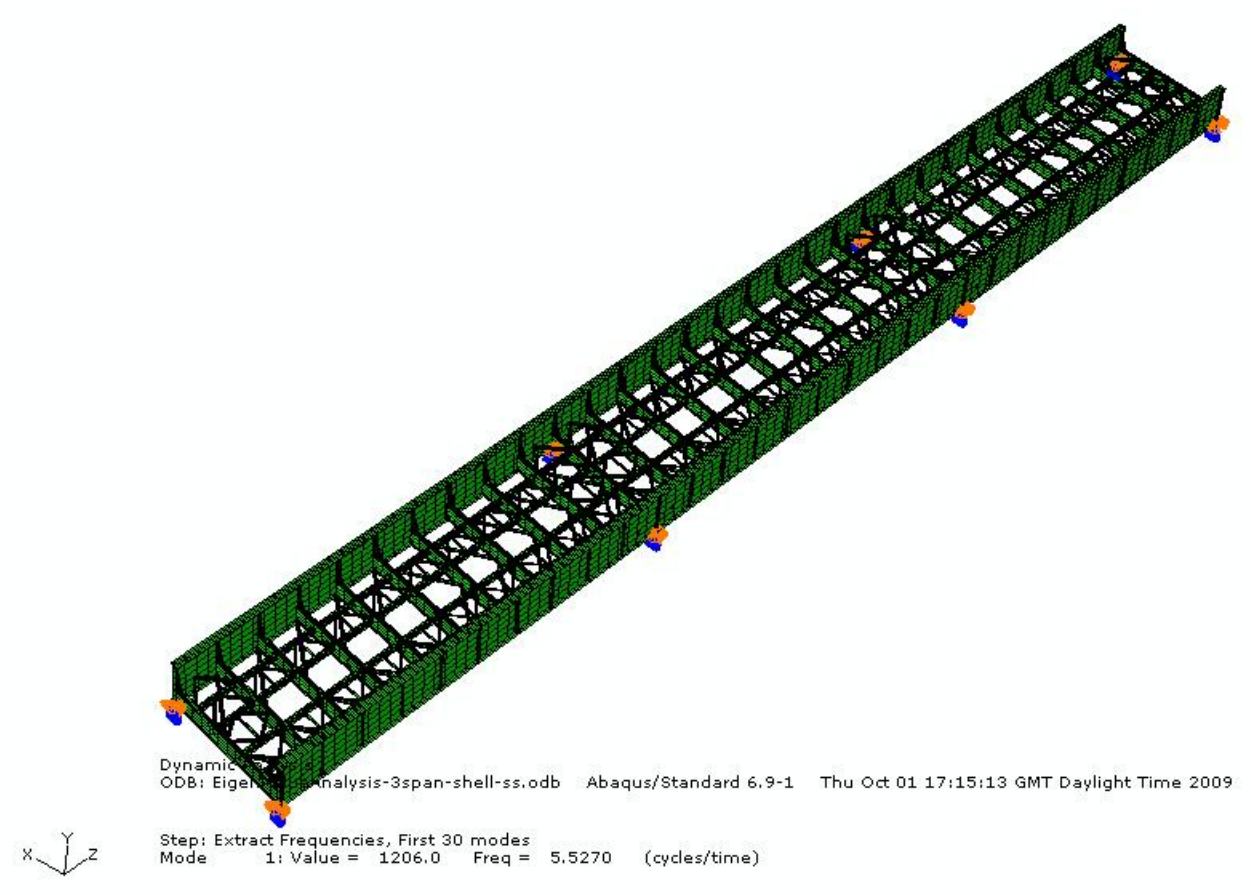

Fig. 6. Three-span shell element FE model of the bridge 


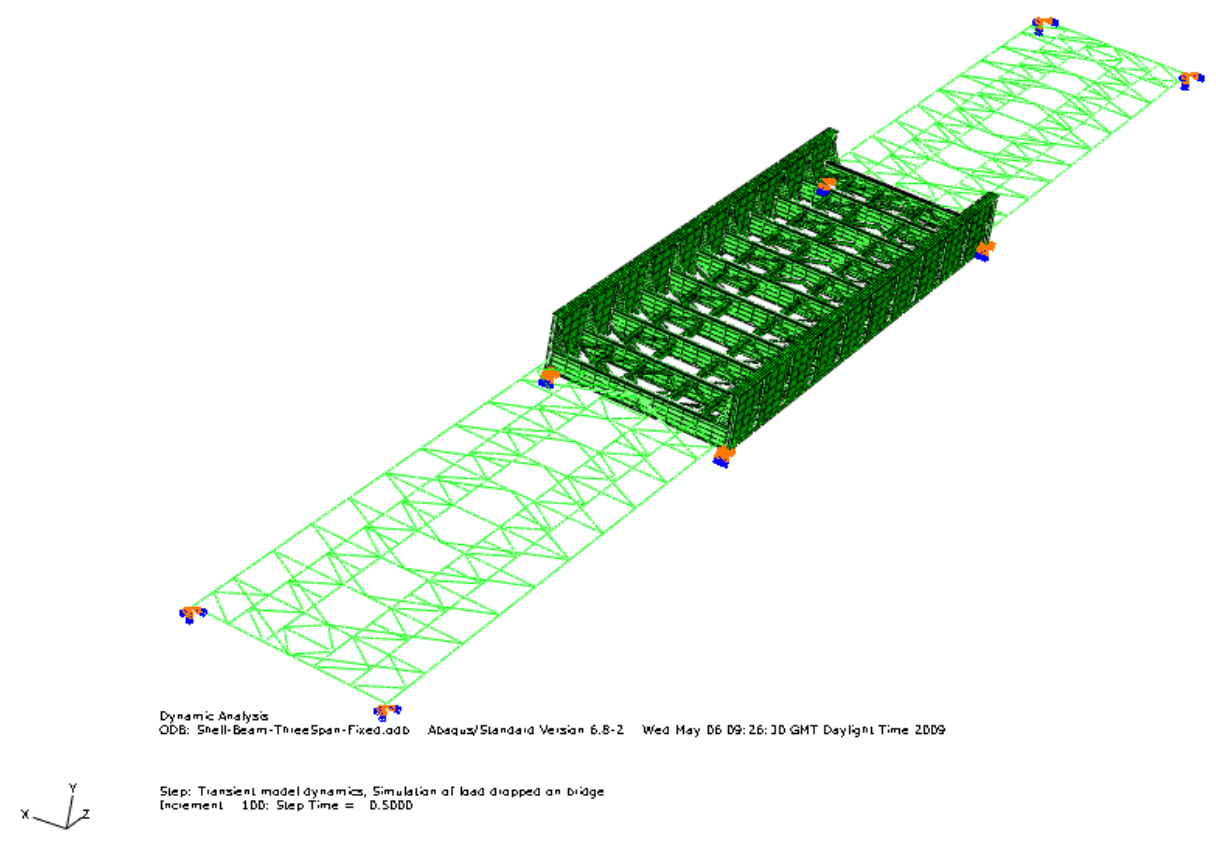

Fig. 7. Three-span beam and shell element FE model of the bridge 


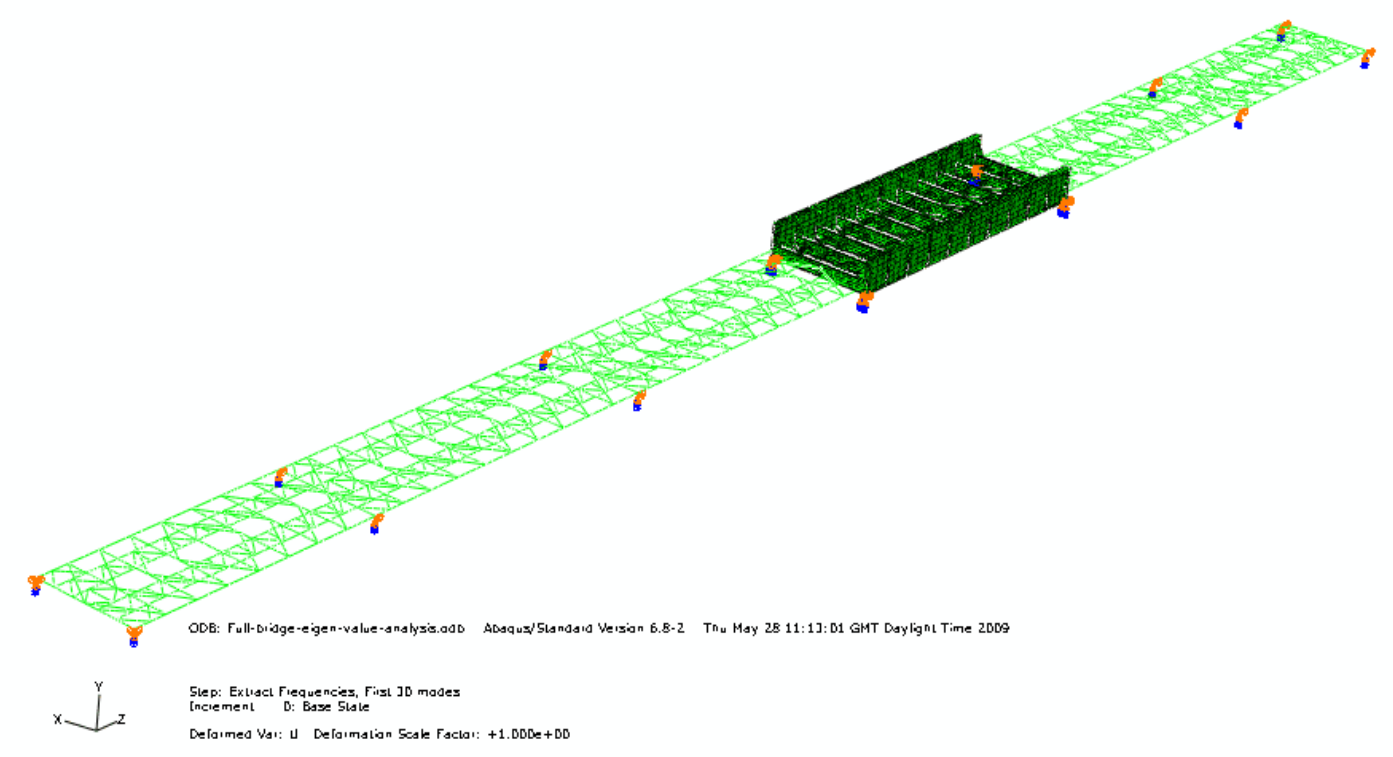

Fig. 8. Beam and shell element FE model of the entire bridge 

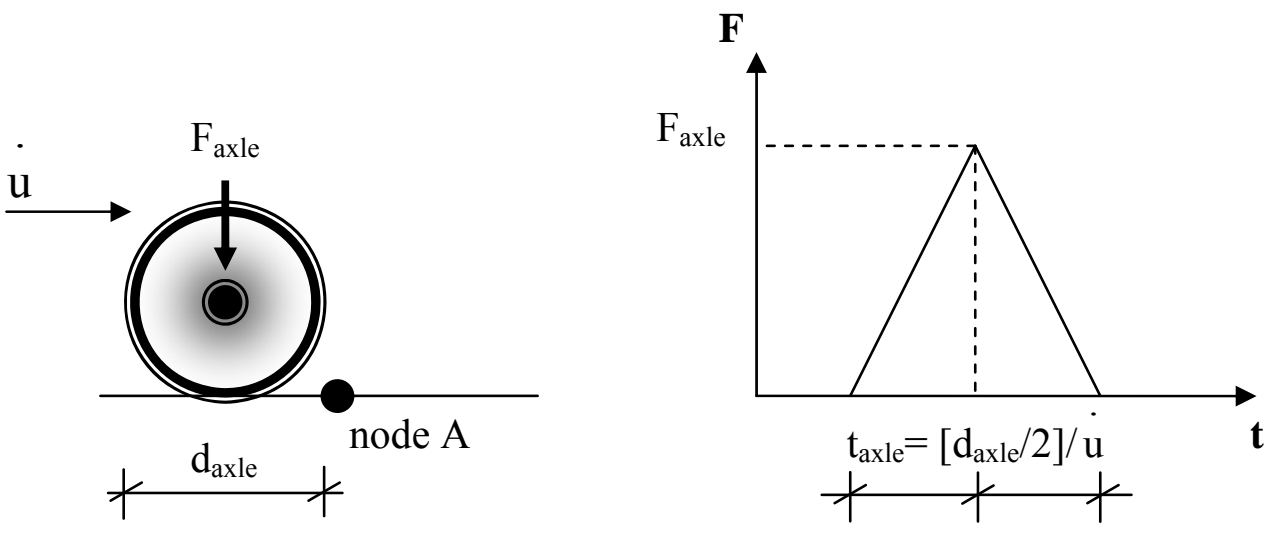

Fig. 9. Force definition at a node in implicit analysis due to an axle load travelling at a velocity u 


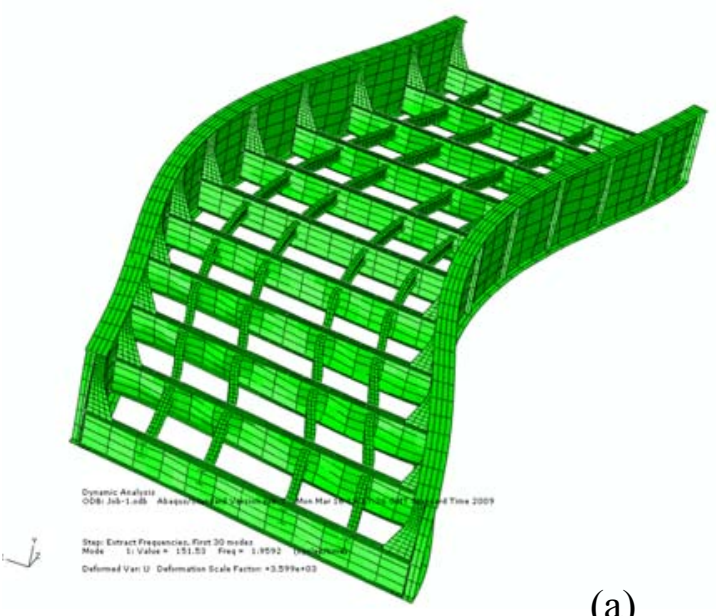

(a)

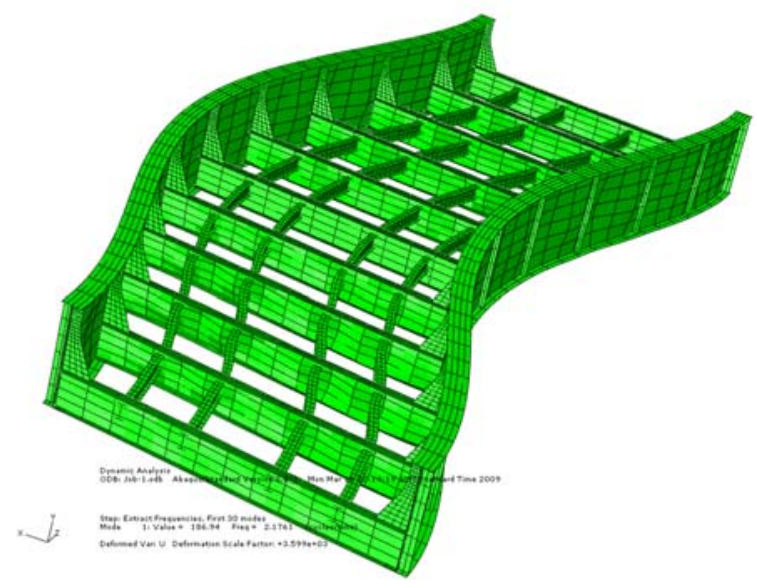

(b)

Fig. 10. First mode shape of single-span shell element FE model without bracings for (a) SS boundary conditions and (b) fixed boundary conditions 


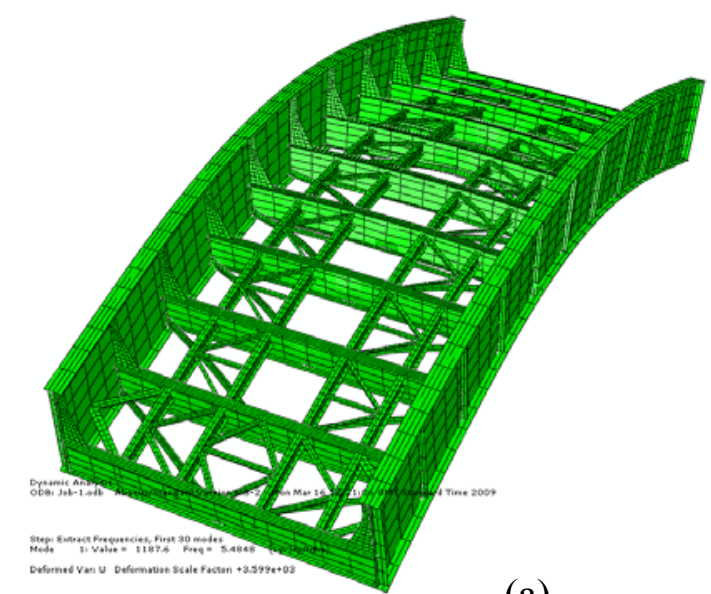

(a)

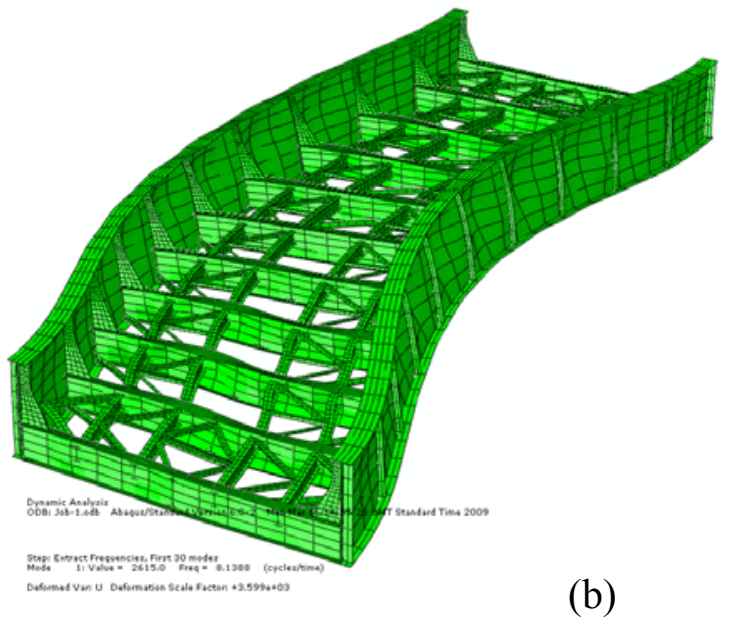

(b)

Fig. 11. First mode shape of single-span shell element FE model with bracings for (a) SS boundary conditions and (b) fixed boundary conditions 

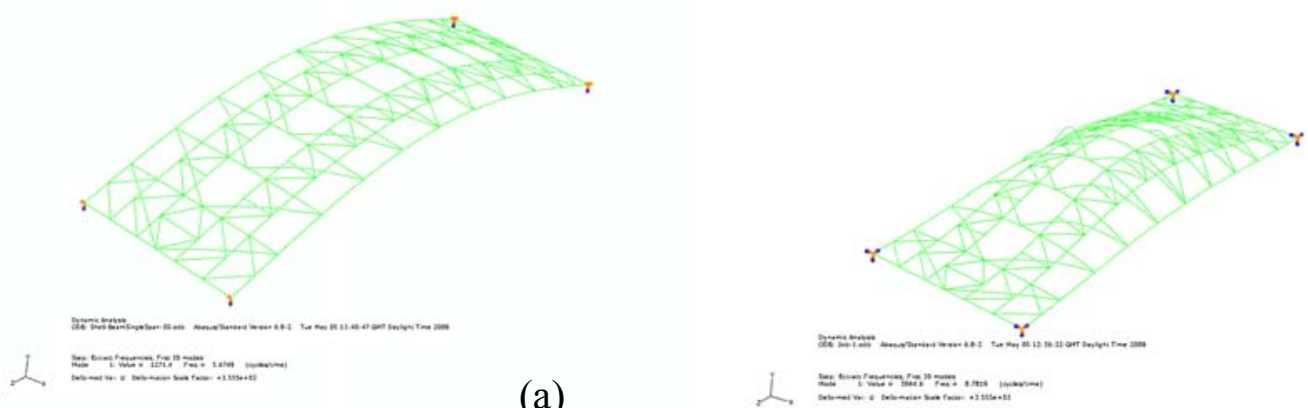

(a)

L. $=-1$

(b)

Fig. 12. First mode shape of single-span beam element FE model with bracings for (a) SS boundary conditions and (b) fixed boundary conditions 


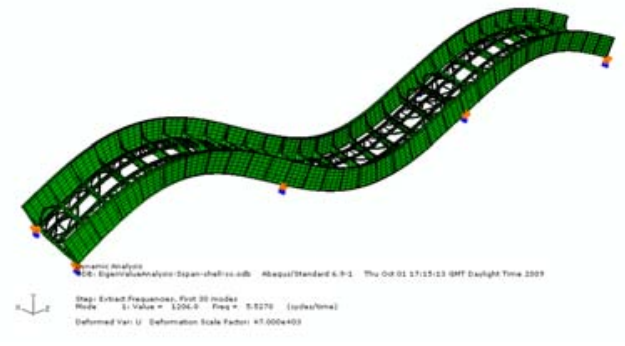

(a) First mode (SS boundary conditions)

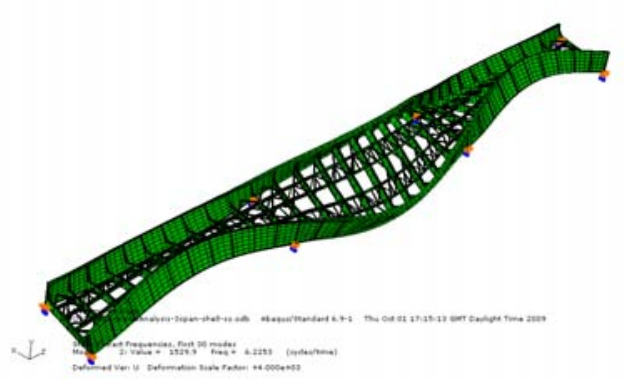

(c) Second mode (SS boundary conditions)

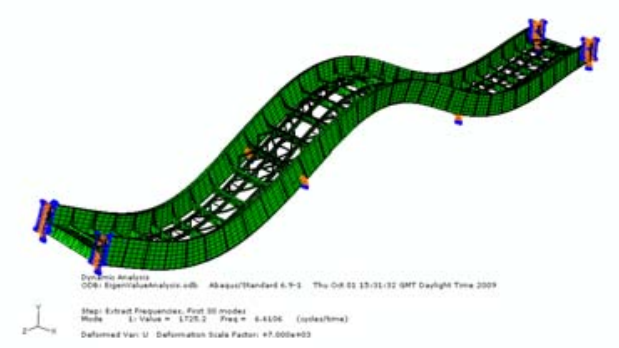

(b) First mode (fixed boundary conditions)

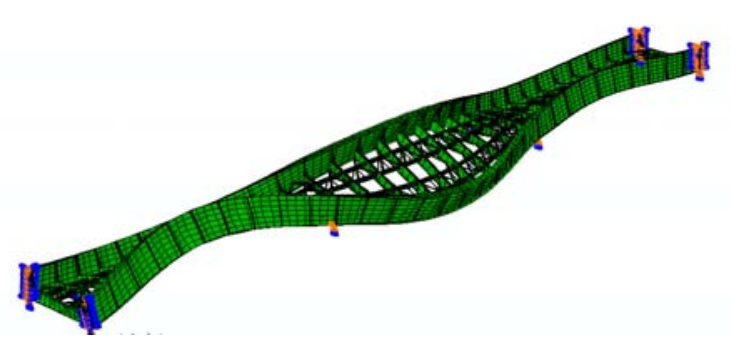

(d) Second mode (fixed boundary conditions)

Fig. 13. Mode shapes of the three-span shell FE model of the bridge 


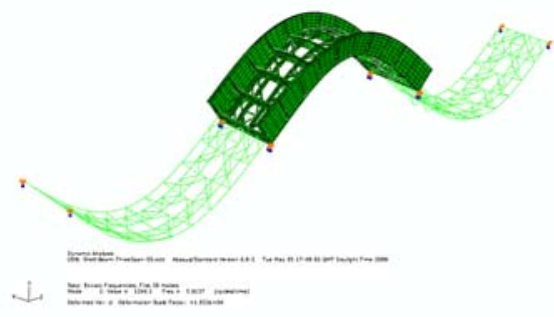

(a) First mode (SS boundary conditions)

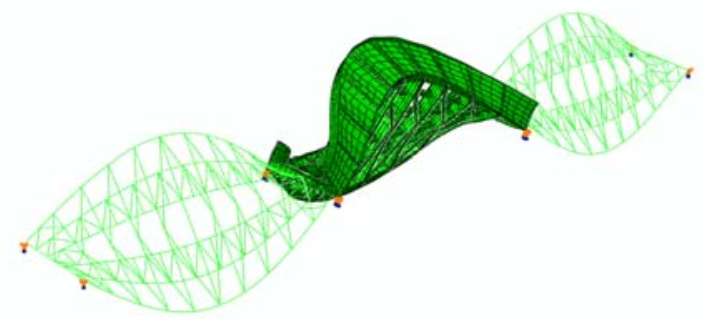

(c) Second mode (SS boundary conditions)

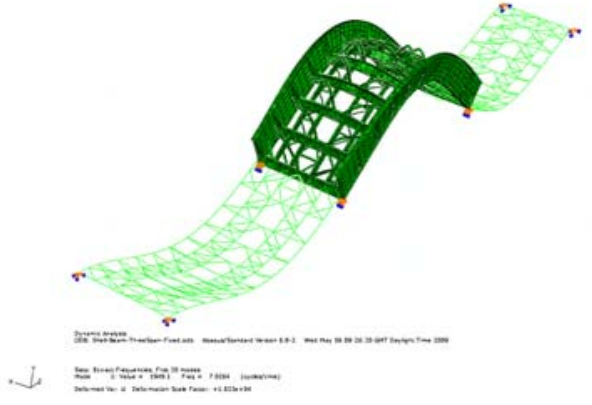

(b) First mode (fixed boundary conditions)

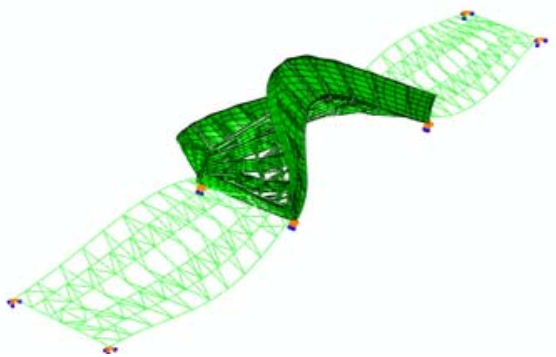

(d) Second mode (fixed boundary conditions)

Fig. 14. Mode shapes of the three-span beam and shell FE model of the bridge 


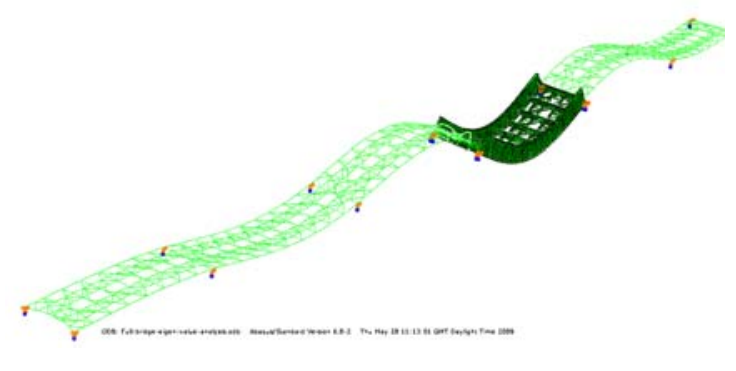

(a) First mode

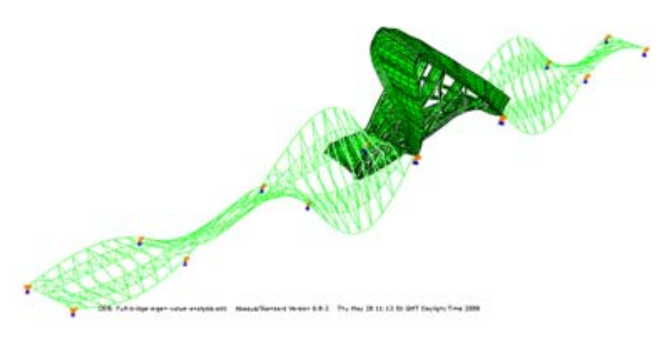

(c) Third mode

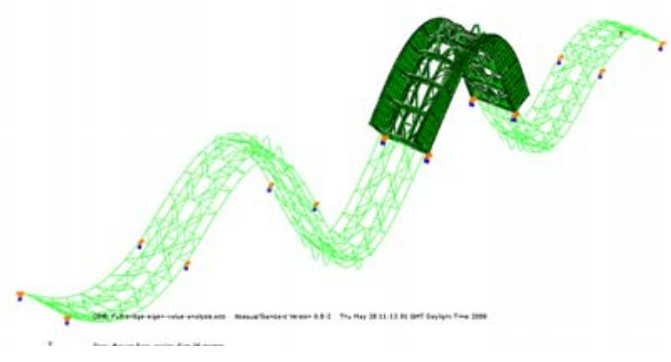

(b) Second mode

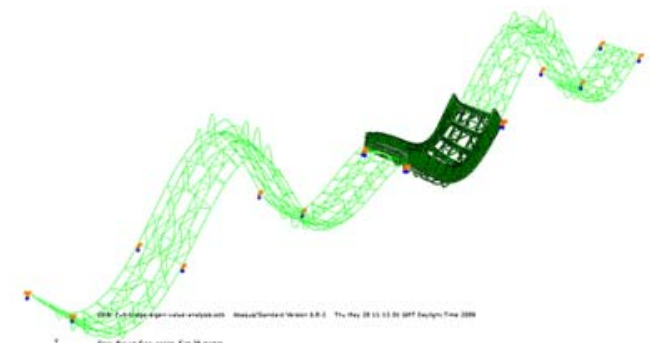

(d) Fourth mode

Fig. 15. Mode shapes of the full FE model of the bridge 


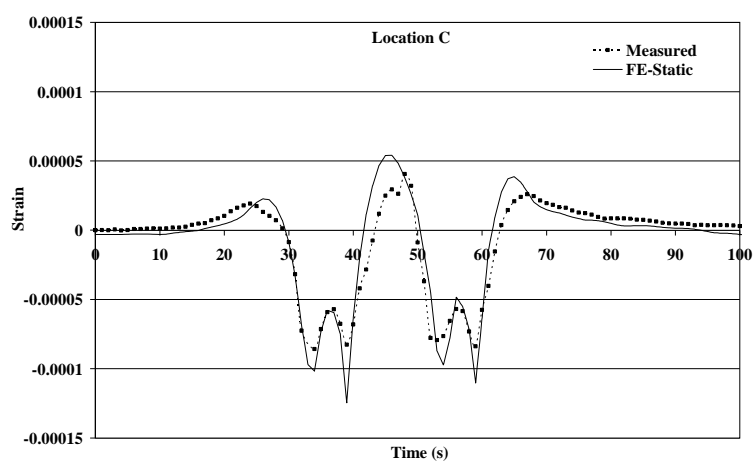

(a) Left top (S1)

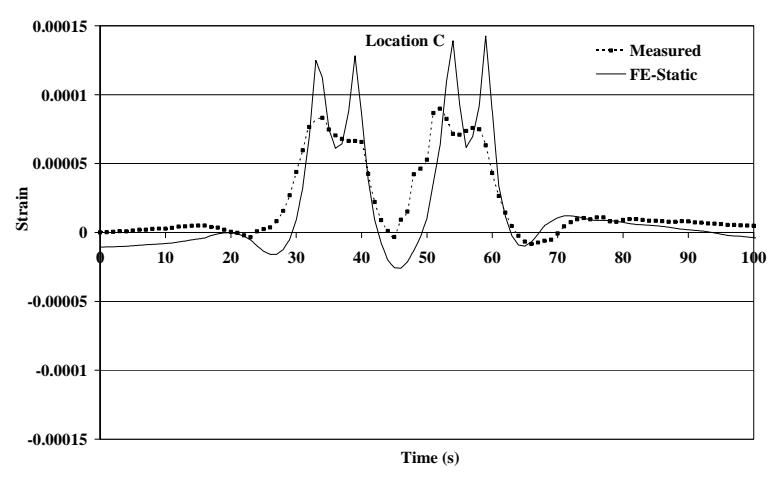

(b) Left Bottom (S2)

Fig. 16. Comparison of strains between field measurements $(1 \mathrm{~km} / \mathrm{h})$ and static FE analysis 


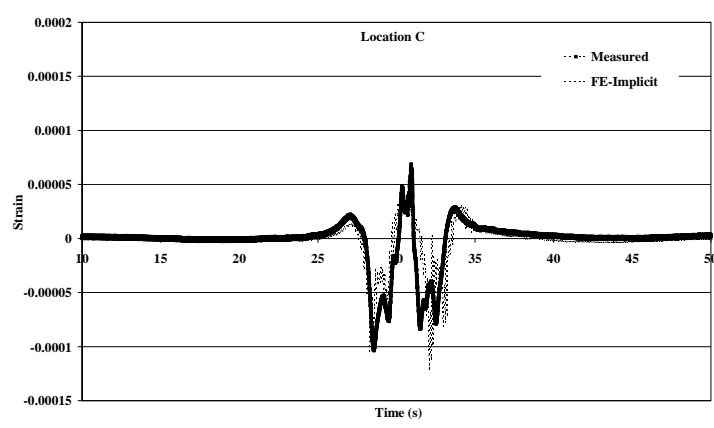

(a) Left top (S1)

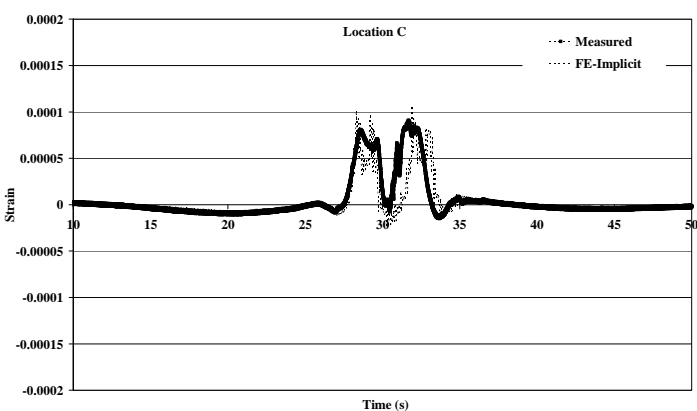

(b) Left Bottom (S2)

Fig. 17. Comparison of strains between field measurements $(10 \mathrm{~km} / \mathrm{h})$ and implicit dynamic FE analysis 


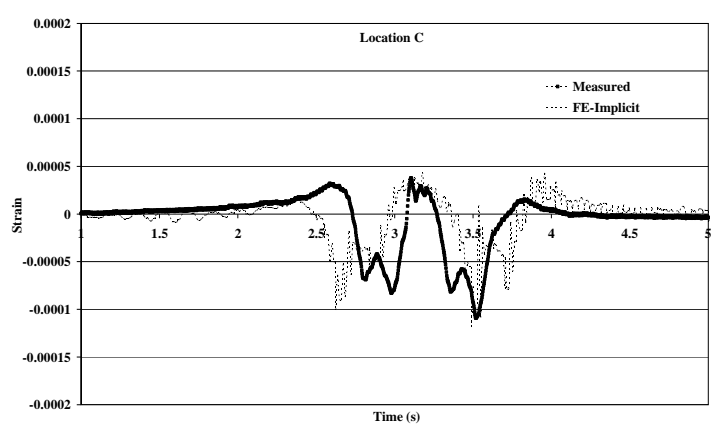

(a) Left top (S1)

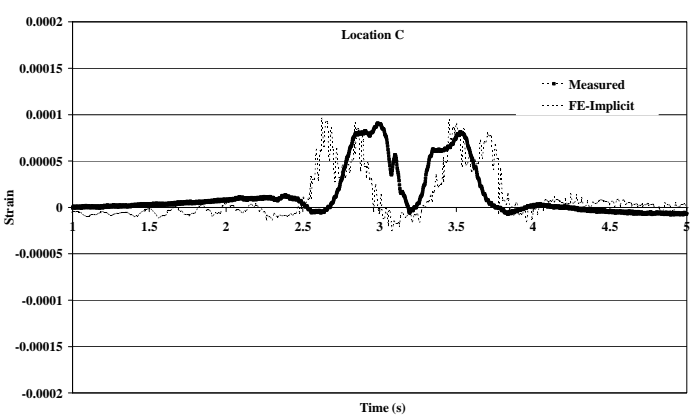

(b) Left Bottom (S2)

Fig. 18. Comparison of strains between field measurements $(52 \mathrm{~km} / \mathrm{h})$ and implicit dynamic FE analysis 


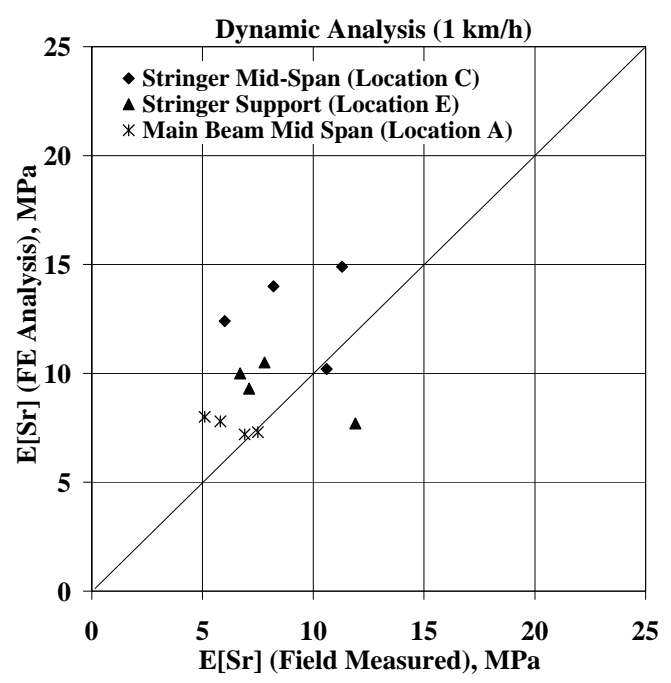

(a) Locomotive speed at $1 \mathrm{~km} / \mathrm{h}$

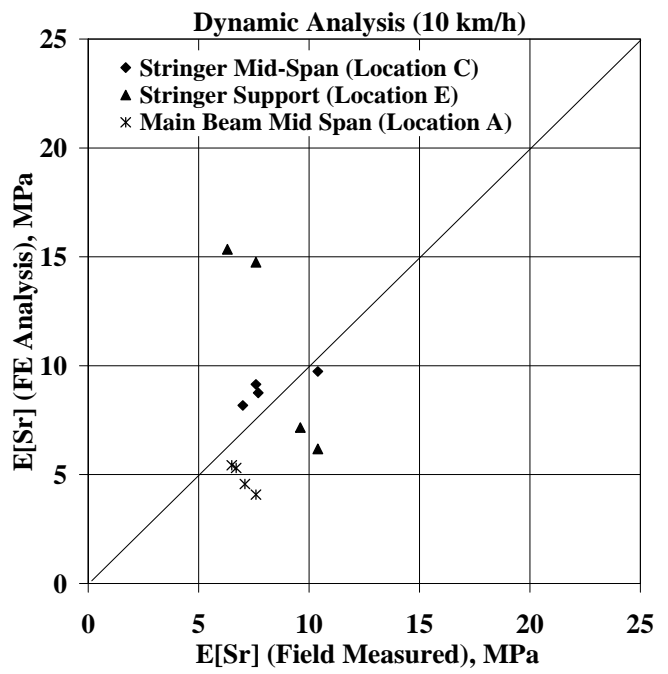

(b) Locomotive speed at $10 \mathrm{~km} / \mathrm{h}$

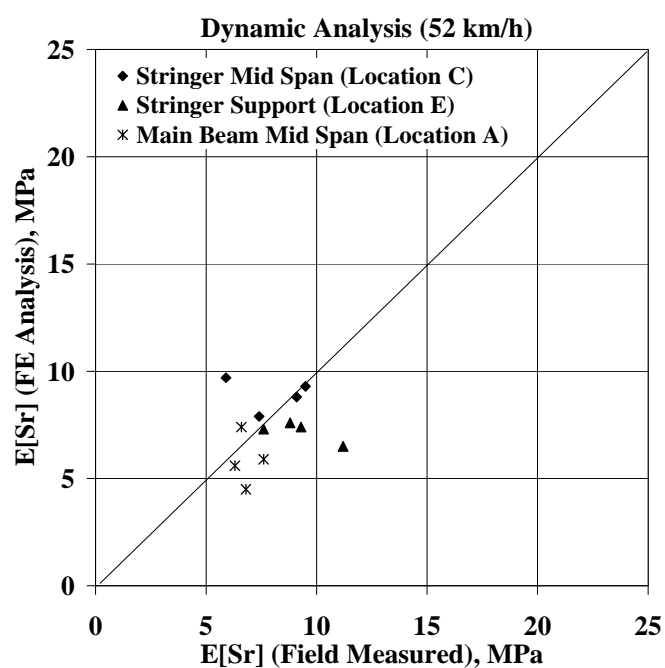

(c) Locomotive speed at $52 \mathrm{~km} / \mathrm{h}$

Fig. 19. Mean stress range comparison for different test locomotive speeds 
Table 1 Comparison of periods for the different FE models

\begin{tabular}{|c|c|c|c|c|c|c|c|c|c|}
\hline \multirow{2}{*}{$\begin{array}{l}\text { No. of } \\
\text { Spans } \\
\text { Model }\end{array}$} & \multicolumn{4}{|c|}{ Single-span } & \multicolumn{4}{|c|}{ Three-span } & \multirow{2}{*}{$\begin{array}{c}\begin{array}{c}\text { Full } \\
\text { bridge }\end{array} \\
\text { Beam- } \\
\text { shell }\end{array}$} \\
\hline & \multicolumn{2}{|c|}{$\begin{array}{c}\text { Shell } \\
\text { Element }\end{array}$} & \multicolumn{2}{|c|}{$\begin{array}{c}\text { Beam } \\
\text { Element }\end{array}$} & \multicolumn{2}{|c|}{ Shell } & \multicolumn{2}{|c|}{ Beam-shell } & \\
\hline $\begin{array}{c}\text { No. of } \\
\text { elements }\end{array}$ & \multicolumn{2}{|c|}{12139} & \multicolumn{2}{|c|}{1318} & \multicolumn{2}{|c|}{35174} & \multicolumn{2}{|c|}{15231} & 17369 \\
\hline $\begin{array}{l}\text { Analysis } \\
\text { time (s) }\end{array}$ & \multicolumn{2}{|c|}{292} & \multicolumn{2}{|c|}{10} & \multicolumn{2}{|c|}{1446} & \multicolumn{2}{|c|}{303} & 701 \\
\hline $\begin{array}{l}\text { Boundary } \\
\text { conditions }\end{array}$ & SS & Fixed & SS & Fixed & SS & Fixed & SS & Fixed & SS \\
\hline $\mathrm{T}_{1}(\mathrm{~s})$ & 0.182 & 0.123 & 0.176 & 0.114 & 0.181 & 0.151 & 0.178 & 0.142 & 0.208 \\
\hline $\mathrm{T}_{2}(\mathrm{~s})$ & 0.156 & 0.086 & 0.148 & 0.114 & 0.161 & 0.148 & 0.152 & 0.137 & 0.164 \\
\hline $\mathrm{T}_{3}(\mathrm{~s})$ & 0.110 & 0.066 & 0.115 & 0.114 & 0.146 & 0.131 & 0.140 & 0.116 & 0.145 \\
\hline
\end{tabular}

